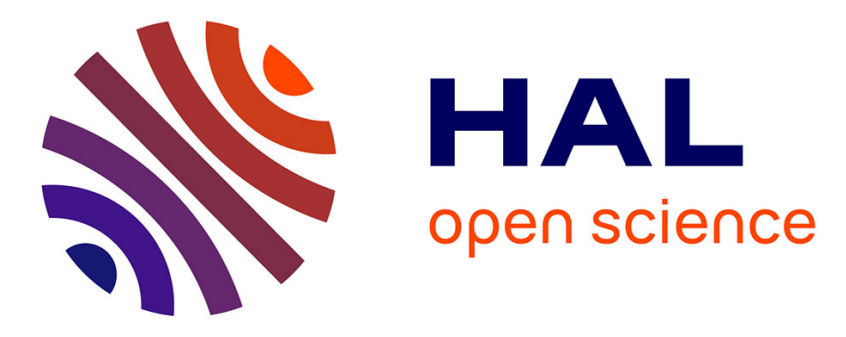

\title{
Modeling students' conceptions: The case of function
}

Nicolas Balacheff, Nathalie Gaudin

\section{To cite this version:}

Nicolas Balacheff, Nathalie Gaudin. Modeling students' conceptions: The case of function. CBMS

Issues in Mathematics Education, 2009, 16, pp.207 - 234. 10.1090/cbmath/016/08 . hal-01557264

\section{HAL Id: hal-01557264 \\ https://hal.science/hal-01557264}

Submitted on 10 Jul 2017

HAL is a multi-disciplinary open access archive for the deposit and dissemination of scientific research documents, whether they are published or not. The documents may come from teaching and research institutions in France or abroad, or from public or private research centers.
L'archive ouverte pluridisciplinaire HAL, est destinée au dépôt et à la diffusion de documents scientifiques de niveau recherche, publiés ou non, émanant des établissements d'enseignement et de recherche français ou étrangers, des laboratoires publics ou privés. 


\title{
Modeling students' conceptions: The case of function
}

\author{
Nicolas Balacheff, Nathalie Gaudin \\ Laboratoire Leibniz \\ IMAG, Grenoble, France
}

\begin{abstract}
We investigate the epistemological complexity of modeling students' knowing of mathematics with the goal of achieving models that acknowledge both the possible lack of coherency and the local efficiency of such knowing. We propose a model of "conception" as a possible tool to answer the epistemological complexity we identify. We then provide an illustration of the usefulness of this model by exploring conceptions of "function" as a case in point.
\end{abstract}

\section{FROM BEHAVIOR TO KNOWING}

The possibility to observe students' learning relies heavily on the indications given by students' behaviors and creations, which are hypothesized to be consequences of the knowings ${ }^{1}$ they have constructed. Such an appraisal is possible and its results are significant only if one is able to establish a valid relationship between the observed behaviors and the inferred knowings. This relationship between behaviors and knowing is crucial, but also problematic. Its problematic nature has been concealed perhaps as a byproduct of the struggle with behaviorism, but it has always been implicitly present in educational research at least at the methodological level. Indeed, a knowing cannot be

\footnotetext{
${ }^{1}$ We follow the choice made in the translation of Brousseau's work (1997) to use the word knowing as a noun and as such to denote a distinction between knowing and knowledge. Knowing refers to students' personal constructs whereas knowledge refers to intellectual constructs recognised by a social body, such as the discipline of mathematics. This distinction corresponds to the distinction made in romance languages between those words that derive from the Latin "cognoscere" and those words that derive from the Latin "sapere".
} 
reduced to its associated behaviors, but on the other hand it cannot be diagnosed, understood, or taught without a characterization based on these associated behaviors.

The importance of this link between behaviors and knowing was clearly pointed out by Schoenfeld (1987) in his introduction to "Cognitive Science and Mathematics Education". Schoenfeld described the cognitive science approach in relation to the effort made to describe in detail problem-solving strategies so that they could be taught and reproduced. We would like to focus on and bring into question the level of description of the behaviors and of their outcomes, as tangible expressions of the problem-solving strategies that Schoenfeld was interested in teaching. In synthesizing his own research at the time Schoenfeld (1987) indicated:

My intention was to pose the question of problem-solving heuristics from a cognitive science perspective: What level of details is needed to describe problem-solving strategies so that students can actually use them? (p.18)

Such inquiry raises for us two essential questions:

- On one hand, to what extent would a finer granularity of the description of these strategies guarantee a better reliability of the learning of a problem-solving strategy? Or, rather, given a competency, does there exist a level of granularity of its description that guarantees the efficient learning of such competency?

- On the other hand, to what extent does a finer description of problemsolving strategies inform us about the relationships between behaviors and knowings?

In their “microgenetic analysis of one student's evolving understanding of a complex subject domain," Schoenfeld, Arcavi and Smith (1993) show that the challenge to be taken up is difficult. Two reasons, which are the main lessons we can learn from 
their seminal study, are at the origin of this difficulty: first, the "highly subjective" character of the empirical data analysis, second what Schoenfeld and his colleagues called the "burden of proof" in showing how behaviors and knowing are related. A way to overcome these difficulties consists of adopting a definition in relation to an explicit characterization likely to reinforce the grounding of the analysis. The present article explores this possibility and provides an illustration. But first, we would like to develop further the issues related to the relationship between behaviors and knowing on which the questions we consider depend.

The question of the relationships between behaviors and knowings is considered as fundamental to the theory of didactical situations (Brousseau 1997). One of the postulates of this theory is that for each knowing that a student could have, there are one or more problem-situation whose demands require certain behaviors from the student that embody that knowing. This fundamental correspondence, established case by case, is justified by the interpretation of problem-situations in terms of games. In the context of this game interpretation, behaviors are seen as expressions of strategies adapted to the representation of the problem-situation attributed to the student (Brousseau 1997, p.215). The basis of that postulate is shared by some approaches to cognitive science: Pichot, (1994, p.206) for example, writes "all behavior implies a knowing." Indeed, this postulate arguably justifies most of our field's research on learning since students' behaviors are the source of the corpus on which we perform our analyses.

Yet the excision of a behavior from the observation of a so-called reality, which could be that of a classroom or a laboratory experiment, requires us to deal at the same time with a methodological and a theoretical problem. An observed behavior is not given by the "reality" but taken out of it as a result of a decision made by an observer (Robert, 1992, p.54). 
If a behavior expresses a relationship between a person and her environment, then it depends on the characteristics of the person as well as on the characteristics of her environment. A good example is the case of instruments: While instruments facilitate action - if the user holds the knowing required to use them — they also restrict the action due to their own limitations (Rabardel 1995, Resnick \& Collins 1994, p.7). One should notice that these limitations could be related to material constraints as well as to the knowings involved in the design of the instruments.

"Person" and "environment" refer to complex realities, not all of their aspects are relevant to the questions we are considering in this paper. About the person, what is of interest to us is her relationship to a piece of knowledge. Thus we refer to the subject as a kind of projection of the person onto her cognitive dimension. In the same way, we are not interested in the environment in all of its complexity, but only in those features that are relevant to a given piece of knowledge. We call milieu such a subset of the environment of a subject; the milieu is a kind of projection of the environment onto its epistemic dimension. In the case of mathematics, the interactions between the subject and the milieu are based on systems of signifiers produced by the subject herself, or by others. We must then extend the classical idea of milieu in order to include symbolic systems and social interaction as means for the production of knowings, as well as the physical milieu to which we generally refer. This is the meaning of Brousseau's proposal to define the milieu as the system antagonist to the subject in the learning process (Brousseau,1997 p. 57).

So, a knowing is neither to be ascribed solely to a subject, nor solely to the milieu. ${ }^{2}$ On the contrary, a knowing is a property of the interaction between the subject

\footnotetext{
2 Taking into account a remark on a previous version of this article, it appears necessary to state clearly the close relationship between what is stated in this paper and the Piagetian model of knowing. However, there is a difference
} 
and the milieu - his or her antagonist system. This interaction is meaningful because its purpose is to fulfill the necessary conditions brought by the situation for the viability of the subject/milieu system. By viability we mean that the subject/milieu system has a capacity to return to equilibrium after some perturbations (for example, a contradiction or an uncertainty) the subject was aware of. The knowing may evolve if the perturbations are such that this is necessary, requiring for this purpose the implementation of a learning process. This is, in other words, a formulation of Vergnaud's postulate that problems are the source and the criteria of knowings (Vergnaud, 1981, p. 220).

In what follows, we introduce the classical problem raised by the possible inconsistency in learner behaviors and ways of understanding (Harel 2006). We present a solution which takes the form of a characterization of students' conceptions and which accounts for their complexity by relating three main features of those conceptions (action, representation, and validation) to the domain in which they are operational. We illustrate the use of this characterization for the case of the concept of function.

\section{AN EPISTEMOLOGICAL PROBLEM}

\subsection{COHERENCE AND SPHERE OF PRACTICE}

The following quotation illustrates the problem of coherence in practice. It comes from the seminal work of the sociologist Pierre Bourdieu on the practices of Algerian farmers over a year's cycle:

\footnotetext{
to be emphasized: our focus is on the whole system [S (subject) $\leftrightarrow \mathrm{M}$ (milieu)] and not on one of its parts. In other words, our concern is not to know "how the subject thinks", but to be able to give account of the whole system in a way relevant to a didactical project — the cognitive system we consider is not $\mathrm{S}$ but $[\mathrm{S} \leftrightarrow \mathrm{M}]$.
} 
"In the diagram of the calendar, the complete series of the temporal oppositions which are deployed successively by different agents in different situations, and which can never be practically mobilized together because of the necessities of practice never require such a synoptic apprehension but rather discourage it through their urgent demands, are juxtaposed in the simultaneity of a single space. The calendar thus creates ex nihilo a whole host of relations $[\ldots]$ between reference-points at different levels, which never being brought face to face in practice, are practically compatible even if they are logically contradictory." (Bourdieu 1990, p. 83).

Thus the location of farmers' practices in a calendar offers a view of practices that allows the observer to find logical contradictions among them; yet those logical contradictions are not necessarily relevant for the farmer who relates to different practices at different times. Bourdieu's explanation of the paradox of the co-existence of rational thinking on the part of the farmer and of knowings which look contradictory from the observer's point of view, can easily be extended to the case of a single person observed in different situations. The core of this explanation is time on one hand, and, on the other hand, the diversity of the situations. Time organizes the person's actions sequentially in such a way that the contradictory knowings are equally operational because they appear at different periods of his or her history: It is reasonable to expect that knowings which are logically contradictory may still ignore each other if they emerge in different situations. The issue of the diversity of situations introduces an element of a different type. This diversity could have several different origins. It may come from a variation of the characteristics of the context (as in the case of problems raised in or out of school), or a variation of the resources (as by making available or not a pocket calculator or a computer), or a variation on the stake of the situation (as in the 
case of a problem being proposed for an assessment or as home work). The existence of this diversity could be seen as an explanation insofar as one recognizes that a knowing is not of a "universal" nature but that, on the contrary, it is related to a specific and concrete domain of validity. Eventually, this means that the transfer from one situation to another is not an obvious process, even if in the eyes of an informed observer the considered situations look isomorphic. For example, the pupils from a primary mathematics classroom may not use the same procedures to compute the total price of a set of items out of school as they do when they add decimal numbers in order to solve a problem proposed by the teacher. Following Bourdieu, we refer to spheres of practice in order to designate these mutually exclusive domains of validity in the history of the subject.

We must insist that although an observer who is able to relate different situations could recognize contradictions, a subject who considers the situations as independent and completely different could ignore these contradictions. However, in the observer's referential system — which is where we are as researchers- these states of the observed subject/milieu system should be labeled in order to show that they relate to the same knowledge, no matter their contradictory nature. So, one often speaks of the subject's knowing of decimal numbers, of continuity of functions, or of line reflection although asserting later that this knowing is not coherent.

To accept the existence of contradictory knowings does not contradict the theoretical principle that these knowings are products of a process of adaptation between the subject and the milieu, ruled by criteria like performance reliability or problem relevance. But this raises educational problems for which solutions have been looked for in different directions. In the following section we review the most significant ones in the case of mathematics. 


\subsection{A DEFINITION FOR A FAMILIAR NOTION: CONCEPTION}

In a survey she presented at the 1986 annual meeting of the American Educational Research Association, Jere Confrey linked the development of research on misconceptions to the acknowledgement of a failure of teaching. Despite all efforts, she argued, many students held major misconceptions in mathematics and science. Confrey noticed that the mathematics education community had a rather pragmatic approach to this problem:

"misconceptions were defined empirically as documented failures of large numbers of students to solve problems which appeared to be related to fundamental concepts." (Confrey 1986, p. 4).

In a paper published later, Confrey (1990) distinguished different approaches to the question, issued from Piagetian genetic epistemology, scientific epistemology, and the information processing approach. In all of them the child-student is seen as a subject fundamentally different from the adult-expert who appears as the owner of the knowledge of reference. ${ }^{3}$ But this view does not exclude the recognition of some sort of cognitive legitimacy of these misconceptions: ${ }^{4}$

“ $[\ldots]$ a child may not be 'seeing' the same set of events as a teacher, researcher or expert. It suggests that many times a child's response is too quickly labeled as erroneous and that if one were to imagine how the child was making sense of the situation, then one would find the errors to be reasoned and supportable" (ibid. p. 29)

Indeed, within the student frame of reference - as opposed to an external onemisconceptions fall under the common rules of knowing:

\footnotetext{
${ }^{3}$ In the case of the former one speaks of "naive theory", "private concepts", "beliefs" or even of the "mathematics of the child" (Confrey 1990 p. 29).
} 
"a misconception does not require the postulation of an inadequate 'picture' of the world; it does require the notion of a successful completion of a number of problems wherein the cycle of problem formulation (expectation), problem-solving (action) and problem reconstruction (re-viewing) are successfully carried out." (ibid.)

In other words: a misconception has a domain of validity, otherwise it would not exist as such. Eventually, there is a very short distance between a misconception and a knowing. The key difference is that for a misconception there exists a refutation known at least to the observer. But even when ascribing the status of a knowing to a misconception ${ }^{5}$, the idea that an intrinsically correct knowledge of reference exists remains a corollary of the initial definition. And yet, such idea is clearly refuted by our current knowledge of the history of science and mathematics. Let us consider, as an example, the evolution of the concept of function.

Bachelard (1938, p.13) wrote in a nice manner that reality is never what one could believe, but is always what one should have thought of. ${ }^{6}$ This statement, formulated in the first half of the twentieth century, expressed that knowing is always in progress. If we accept this, then errors witness the inertia of the instrumental power of a knowing which has proved itself by its efficiency in enough situations, but which appears badly adapted in new situations.

A main achievement of research of the 80's on students' ways of understanding is the recognition that errors are not only the effect of ignorance, of uncertainty, of chance, but the effect of previous knowings which were interesting and successful, but which now are revealed as false or simply not adapted (Brousseau 1997, p. 82). In one

\footnotetext{
4 This remark, made in the case of the scientific epistemology, is in fact valid for all the three mentioned approaches, even for the Piagetian approach as we emphasise it in the following paragraph.

5 What led most authors to abandon the word misconception.
} 
of the first studies within this paradigm, Salin (1976) proposed cognitive characteristics of errors that became essential to the development of the theory of didactical situations. On the one hand an error is a point of view of a knowing about another knowing (possibly for a subject, the evaluation of an older knowing from the point of view of a new one), and, on the other hand, an error can be identified only if the feedback from the milieu can be "read" by the subject as the indication of a failure (a non satisfied expectation).

The main difference between the previous position and the current one lies in their epistemological meaning; the status of a knowing is different in each case. The first position implies the existence of a knowing-of-reference general and true (what encapsulates the common use of the word knowledge in English). The second position requires only establishing a relationship between two knowings with the idea of an evolution, without judgment on them. More precisely, from the second perspective a knowing is considered as a set of conceptions which are activated depending on contextual characteristics. These conceptions, whether they appear erroneous, partial, or ill-adapted to an observer, are first of all the results of an optimal adaptation of the subject/milieu system following criteria of relevance and of efficiency to a situation-in other words, an adaptation to a problem-situation. The corollary of this perspective is that a conception has a provisional character: It could be revisited in the course of the adaptation process to produce a new conception; this is especially desirable when the new conception corresponds to a content to be taught (Balacheff and Margolinas 2005).

\subsection{A PRAGMATIC DEFINITION OF CONCEPTION}

The word "conception" has been used for years in research on teaching and learning mathematics. It functions as a tool, but its definition remains implicit; it has not

\footnotetext{
6 “Le réel n'est jamais “ ce qu'on pourrait croire ” mais il est toujours ce qu'on aurait dû penser” (Bachelard, 1938,
} 
yet been taken as an object of study per se. According to Artigue (1991, p. 266), "conception" refers to a local object; in this sense its epistemological status does not really differ from the one of the word "misconception." Together with Vinner (1983, 1987), we think that there is a need for a better-grounded definition of conception. The expectation is that a better definition will allow us to analyze the differences and commonalties between conceptions, in such a way that we will have a better ground to design learning situations.

The first raison d'être of the notion of conception in educational research is the need to conceptualize the specific states of equilibrium achieved by the subject/milieu system satisfying some viability constraints of a situation. These constraints do not address the way the equilibrium is recovered but the criterion of this equilibrium. Following Stewart (1994, pp. 25-26) we would say that these constraints (a) are proscriptive, which means that they express necessary conditions to ensure the system's viability and (b) are not prescriptive since they do not tell in detail how an equilibrium must be reached.

We can now propose a definition of "conception" which can be pragmatically and efficiently used in a didactical problématique.

$A$ conception is the state of dynamic equilibrium of an action/feedback loop between a subject and a milieu under proscriptive constraints of viability. 


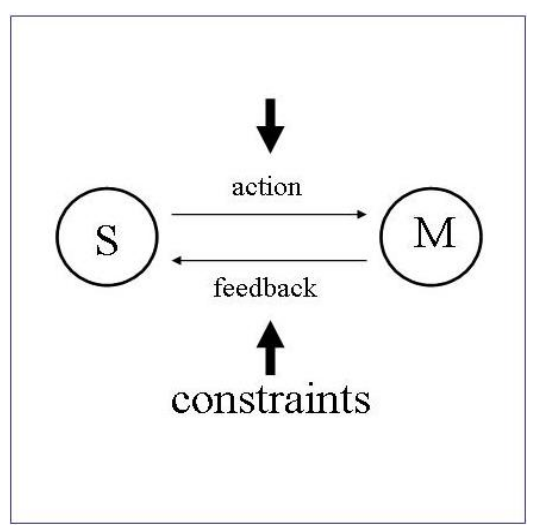

Figure 1

From a didactical perspective, we are interested in the nature of the proscriptive constraints that the subject/milieu system must satisfy. Among these constraints, not known exhaustively, we can mention two that are specific of didactical systems: time constraints and epistemological constraints (Arsac et al. 1992). The former are due to the way schooling is organized (duration of school life, organization of the school year, organization of the lessons, etc.). The latter is due to the existence of a domain of knowledge of reference which underlies the content to be taught and learned and which de facto provides criteria to the acceptability of any learning outcomes.

The role of the teacher, with respect to a given content to be taught, is to organize the encounter between a subject and a milieu so that a conception (acceptable to the didactical intention) can be identified as a result of the evolution of their interactions. Such an encounter is not a trivial event. To create an environment that facilitates it, it is not enough for the student to just be able to "read" in her environment the milieu relevant to the teaching purpose (Balacheff, 1998). The student also needs to select the relevant features of the environment, to identify the feedback, and to understand it with respect to the intended target of action. To succeed in this task, the teacher must construct a situation that allows the devolution to the students of both the milieu and the relevant relationships (action/feedback) to this milieu. But the didactical 
intention of such a situation can act as a constraint; this is the case when the student believes in a teacher expectation, what could modify the nature of the subject/milieu system equilibrium and then the nature of the related conception. There resides the basic complexity of didactical systems.

Learning is a process of reconstruction of an equilibrium of the subject $/ \mathrm{milieu}$ system which has been lost following perturbations of the milieu, or perturbations of the constraints on the system, or even perturbations of the subject herself (modification of her intentions, or as a consequence of a brain disease, etc.). The didactical problématique considers the case of perturbations provoked on purpose, with the intention to stimulate learning. The indicator of a perturbation is the gap, recognized by the subject, between the expected result of an action and the actual feedback from the milieu. This means on one hand that the subject is able to recognize the existence of a gap not acceptable with respect to her intention, and, on the other hand, that the milieu can provide identifiable feedback.

Sometimes the subject does not identify a gap whereas we, as observers, see that a gap should have been recognized. We call this unnoticed gap an error when it is the symptom of a conception, that is: the symptom of the resilience of a previous equilibrium of the subject/milieu system.

In the following section we propose a model of "conception" complementary to its definition, which intends to provide an effective tool to concretely represent and analyze the corpora of data that can be constructed from the observation of students' activities. We will then take an example, the case of function.

\subsection{FROM A DEFINITION TO A MODEL OF CONCEPTION}

We model a conception $\mathrm{C}$ by a quadruplet $(\mathrm{P}, \mathrm{R}, \mathrm{L}, \mathrm{\Sigma})$ in which:

- $\mathrm{P}$ is a set of problems; 
- $\mathrm{R}$ is a set of operators;

- $\mathrm{L}$ is a representation system;

$-\sum$ is a control structure.

Relating this model to the definition proposed in the preceding section, one can see that:

- P corresponds to the class of the disequilibria the considered conception is able to recover; in mathematical terms: the problems it allows to be solved - in pragmatic terms we will speak of the sphere of practice of the related conception;

- R corresponds to the set of operators needed either to perform "concrete" actions on the milieu, or to transform and manipulate linguistic, symbolic or graphical representations.

- L describes the linguistic, graphical or symbolic means which supports the interaction between the subject and the milieu, either actions or feedback, as well as their outcomes.

- $\sum$ is needed to describe the components which support the monitoring of the equilibrium of the $[\mathrm{S} \leftrightarrow \mathrm{M}]$ system;

The first three components of this quadruplet, have been borrowed from the characterization that Vergnaud (1991, p. 145) ${ }^{7}$ proposed for a conceptual field. We have introduced the fourth component in order to explicitly take into account the dimension of validation which is critical to mathematics and mathematics learning.

The very first question that this model must contend with is that of how it relates to the "reality" of students ways of understanding as they have been studied and

\footnotetext{
${ }^{7}$ This definition proposed by Vergnaud was in fact coined at the beginning of the 80 's.
} 
reported until now in our community of researchers. We consider this question for each of the four elements of the quadruplet.

The question of the concrete characterization of the set $P$ of problems is difficult. One option would be to consider the set $\mathrm{P}$ to include all the problems that a conception provides efficient tools to solve. This was the option suggested by Vergnaud (1991) for the case of additive structures, but it appears that such an exhaustive description is in most cases out of reach. Another option is to consider P to be a finite set of problems from which other problems can be derived. This is the solution proposed by Brousseau (1997, p. 30). Whereas that would be the most elegant way to proceed, we presently don't know if such a generative set of problems can be constructed in order to describe the sphere of practice of any conception. Instead, the pragmatic position that we can presently implement consists of deriving the description of the set $\mathrm{P}$ from a careful task analysis and in an empirical way, by building on a continuously developing understanding of the genetic and epistemic complexity of the mathematics considered. This approach can be strengthened by the analysis of historical and actual uses of mathematics (e.g. D'Ambrosio,, 1993; Lave, 1988; Nuñes et al., 1983; Sierpinska, 1989; Thurston 1994). This approach also reveals the duality of problems and conceptions which Soury-Lavergne (2003) has studied using the characterization we present here as a tool.

The question of the concrete characterization of the set $R$ of operators is more classical. Operators are means to change the relationship between the subject and the milieu; they are the tools for action. Operators could be concrete, allowing the performance of actions on a material milieu, or abstract, allowing the transformation of linguistic, symbolic, or graphical representations. So, an operator could take the form of functionality at the interface of a piece of software, or of a syntactic rule to transform an algebraic expression, or it could even take the form of a theorem in an inference. 
The representation system $L$ consists of a repertory of structured sets of signifiers $^{8}$, which may or may not be of a linguistic nature, used at the interface between the subject and the milieu, supporting action and feedback, and operations and decisions. Just to mention a few examples: algebraic language, geometric diagrams, natural language, but also interfaces of mathematical software and calculator keys are all examples of structured sets of signifiers. For a given conception, one or more of them can be assembled into a representation system. Whatever it is, depending on the state of the subject/milieu system, the representation system must be adequate to give account of the problems and to allow operators to perform.

The last dimension of a conception, the control structure $\sum$, is made up of all the means needed to make choices, to take decisions, and to express judgment. This dimension is often left implicit although one may realize that the criteria which allow one to decide whether an action is relevant or not, or whether a problem is solved, is a crucial element in understanding a mathematical concept. We would suggest that, in Vergnaud's seminal proposition, the control structure is implied by his reference to theorems-in-action or to inference (Vergnaud, 1991, pp. 141-142), which are meaningful notions only to the extent that they are associated with the recognition that the subject has procedures to check whether his or her actions are legitimate and correct. After Pölya and a long tradition of research on metacognition, Schoenfeld (1985, pp.

\footnotetext{
8 We are aware of the difficulty which could be raised by the use of the word "representation," especially when it is read in the light of a psychological problématique. We do recognize that any "symbol as representation needs a living person who constructs the representation, or in comprehending reconstructs it” (Furth, 1969, p. 93). But we are here focusing on the system formed by a knowing subject and a milieu, not on any one of them in isolation. Indeed, representation in our sense - which is a semiotic sense - is the basic support of the observed behaviors. We neither mean to reduce the subject or the knowledge to the signifiers. Nor do we reduce the representation systems to a set of signifiers, which we consider in the context of semiotic registers as conceptualized by Duval. It is on purpose that our approach is limited here. For more detailed considerations, the reader can see Balacheff and Margolinas (2005).
} 
97-143) has shown the crucial role of control in problem solving. More recently, Robert (1993) emphasized the role of meta-knowledge demonstrating the need to treat control structures as such. Indeed this is directly related to a problématique of validation, which is intrinsically related to understanding (Balacheff, 1987, p. 160).

It is important to insist that this model of a conception aims at accounting for the subject/milieu system, and is not restricted to one of its components, in that the representation system allows the formulation and the use of the operators by the active sender (the subject) as well as the reactive receiver (the milieu). The control structure allows us to express and discuss the means of the subject to decide on the adequacy and validity of an action, as well as the criteria of the milieu for "selecting" a feedback.

\section{THE CASE OF FUNCTIONS}

\subsection{AN EXTENSIVELY STUDIED THEME}

Instead of giving many examples, which we could explore only superficially in the limited space of the present article, we have chosen to investigate in a manner as precise as possible just one case, namely the case of "functions." The theme of function has been extensively studied. Many bibliographical references are available, all very different from one another. The notion of function is also at the intersection of several mathematical areas (numbers, limit, algebra, etc.) and requires considering several representation systems (graphical representations, symbolic language, etc.). All of that makes functions an important candidate to exemplify our approach.

The following are classical ways to categorize conceptions of function:

- Function is a correspondence "law" (a function expresses the correspondence between two sets, an element of the first set being associated with a unique element of the second set) 
- Function is a symbolic expression (a formula)

- Function is a graphical object

The two first formulations come from Vinner and Dreyfus (1989, pp. 359-360). As the reader may know, these authors consider other conceptions of "function", such as "relation of dependence", "rule" and "operation". Other authors introduce other categories like "ratio and proportion" or "functional dependency" (Sierpinska, 1989) or function-as-processes (Breidenbach et al., 1992). These categories can be seen as refinements of the more general ones mentioned above. Because of the fragility of the means we have to ascribe a conception to a student, we chose here to remain with the three main categories mentioned above.

The methods used to ascribe a conception to a student have usually included analyzing interviews or questionnaires. These instruments have often asked students whether there exists a function corresponding to a given specification (e.g., Vinner and Dreyfus, 1989, p. 359), engaged students in modeling some situations (e.g., Breidenbach et al., 1992, p. 279), or even posed students the question "what is a function for you?" (Vinner and Dreyfus, 1989, p. 359). What students produce then is rather difficult to analyze. For example, one may wonder how it is possible to distinguish precisely between the category "dependency relationship between two variables" ("relation of dependence") and the category "something which relates the value of $x$ to that of $y$ " ("rule"). The issues pointed at here are, on one hand, that of the way data are collected and its effect on the diagnostic of conceptions, and on the other hand, that of the way in which these conceptions can be described.

The categories we have selected can be seen as invariant in the mathematics education literature, they in fact correspond to the three main representation systems associated to "function"- - whether one considers research in mathematics education or research in history of mathematics. Indeed, it is by the historical analysis, using the 
classical works of several historians (Edwards, 1979; Kleiner, 1989; Kline, 1972; Smith 1958), that we will introduce a first proposition for modeling the conceptions of "function".

\subsection{CONCEPTIONS OF FUNCTION FROM A HISTORICAL PERSPECTIVE}

A good starting point to identify the main conceptions of "function" in the course of the history of mathematics is to distinguish them by means of the main system of representation they implemented.

One of the most ancient signs of the existence of function is tables and their uses. For example, Ptolemy (in the Almagest) knew that positions of planets change with time and compiled astronomical numerical tables (Youschkevitch 1976, p.40-42). Arabian astronomers in the $10^{\text {th }}$ and $11^{\text {th }}$ Centuries also used precise tables. Tables go with locating an isolated number using another number (or quantities), and so, the idea of variable is not yet present.

The association of curve with table played a critical role in formulating and solving the problem of determining the trajectories of the planets. Kline (1972, p. 336), for example, indicates that Kepler improved the computation of the position of planets essentially by adjusting geometrical curves and astronomical data, without any theoretical reference to explain why he considered the trajectories to be elliptical. The validity of the conjectured trajectories was then essentially related to the precision of the measurement of the planet positions and to the choice of a familiar geometric object, the ellipse, that permitted the description of the universe with simple mathematical laws. Kline (1972, p. 338) notes that most of the functions introduced in the 17th century were first studied as curves. In fact, curves, as trajectories of moving points, were the main object of study for mathematicians of that time (Kleiner, 1989, p. 283). 
The creation of the symbolism of algebra (by Viète, and later Descartes, Newton, and Leibniz) was decisive for the development of the concept of function. The separation of the study of functions from geometry is credited to Euler. Kleiner (1989, p. 284) emphasizes that Euler's "Introductio in analysin infinitorum" (1748) offers an entirely algebraic approach without a single picture or drawing. The function was presented as the central object of the Analysis. The analytic characterization of functions received a strong formulation by Euler, who stated that a function is an analytical expression formed in any manner from a variable quantity and constants.

Although considering a function as an analytical expression proved to be a powerful tool, it led to contradictions and was inadequate to solve some problems of the $18^{\text {th }}$ century (e.g. the controversy of the vibrating strings). In 1755, Euler formulated a general definition of function expressing the notion of dependence between variable quantities and the notion of causality (Dhombres, 1988, p. 45). The potential of such a definition, along with the difficulties it brought along, stimulated many discussions up to the $20^{\text {th }}$ century (Monna, 1972).

Each of these conceptions ${ }^{9}$ can be represented by a quadruplet in the form we advanced above:

- Table conception: $\mathrm{C}_{\mathrm{T}}=\left(\mathrm{P}_{\mathrm{T}}, \mathrm{R}_{\mathrm{T}}\right.$, Table, $\left.\Sigma_{\mathrm{T}}\right)$,

- Curve conception: $\mathrm{C}_{\mathrm{C}}=\left(\mathrm{P}_{\mathrm{C}}, \mathrm{R}_{\mathrm{C}}\right.$, Curve, $\left.\sum_{\mathrm{C}}\right)$,

- Analytic conception: $\mathrm{C}_{\mathrm{A}}=\left(\mathrm{P}_{\mathrm{A}}, \mathrm{R}_{\mathrm{A}}\right.$, Algebra,$\left.\sum_{\mathrm{A}}\right)$.

- Relation conception: $\mathrm{C}_{\mathrm{R}}=\left(\mathrm{P}_{\mathrm{R}}, \mathrm{R}_{\mathrm{R}}, L_{R}, \sum_{\mathrm{R}}\right)$

The cases of Table, Curve and Algebra conceptions are sufficient to illustrate our purpose, and so we will not develop in detail the case of the Relation conception.

\footnotetext{
${ }^{9}$ We do not claim that these four conceptions are sufficient in order to give account of the historical development of "function". They are milestones from which the historical analysis may be carried out and organised.
} 
The words "Table", "Curve", "Algebra" are used to refer to the corresponding representation systems (which is not the case for the Relation conception) that are characterized by their specific syntactic rules and their own criteria for validity. The question is then to examine for $\mathrm{C}_{\mathrm{T}}, \mathrm{C}_{\mathrm{C}}$ and $\mathrm{C}_{\mathrm{A}}$ whether their defining componentsrespectively the sets $\mathrm{P}$ of problems, the sets $\mathrm{R}$ of operators and the control structures $\sum$ - show significant differences depending on the conception they aim to describe. We consider these differences from the point of view of the control structures.

The Table conception $\mathrm{C}_{\mathrm{T}}$ has essentially empirical foundations; the validity of a table depends on the precision of measurement and of the related computations against the requirements of a given experimental context. In the case of the Table conception, which we ascribe to Kepler, the validity must be evaluated against the quality of the interpolations and predictions that the ellipse allowed. Therefore the corresponding control structure $\sum_{\mathrm{T}}$ was fundamentally of an empirical nature, providing the means that allowed the precision of tables to be verified with reference to the observations and to the measurements that had been carried out. However, the input/output table is the first means of representation used, the means by which quite a number of functions were shaped. Kline (1972, p. 338) reminds us that the table of the sine function was known with great precision long before the associated curve became a mathematical object. Then, the validity of the solution of a problem from the corresponding sphere of practice $\left(\mathrm{P}_{\mathrm{T}}\right)$ did depend in an essential manner on the quality of rather concrete productions and of actions necessary to collect and treat data. 
This also applies to the Curve conception whose corresponding sphere of practice $\left(\mathrm{P}_{\mathrm{C}}\right)$ - in the beginning of the 18th century — was constituted by the important problem of long distance navigation where coasts were out of sight. ${ }^{10}$

Thus the set of problems $\mathrm{P}_{\mathrm{T}}$, as well as $\mathrm{P}_{\mathrm{C}}$, were dominated by practical questions and $\mathrm{R}_{\mathrm{T}}$, as well as $\mathrm{R}_{\mathrm{C}}$, included — but not exclusively—techniques of measurement, computation, and drawing. We might even suggest that the ellipse of Kepler's first law was a geometrical object, ideally conceived of, but empirically used when constructing curves in order to access objects and to make predictions. A curve was not yet the graphical representation that we acknowledge nowadays as being the graph of a function considered as a relationship between entities (numbers or even quantities).

The Analytic conception $\mathrm{C}_{\mathrm{A}}$ is of a different nature; it introduces a rupture in the epistemology of functions. A function defined by an analytical expression does not need to refer to an experimental field (either of natural phenomena or of mechanical drawings). It can be studied for itself, as Euler did by presenting functions as the object of study — what was called Analysis (Introductio in analysin infinitorum). That does not mean that the problématique of modeling no longer plays any role; rather, it means that it is no longer central and does not characterize the conception. A purpose of the Analysis of the $18^{\text {th }}$ Century (and of the $19^{\text {th }}$ and $20^{\text {th }}$ Centuries) was the solution of functional equations, which were of great importance in Physics (Dhombres, 1988), and the developments into infinite series, which played a central role as operators $\left(R_{A}\right)$ in those solutions. The corresponding control structure $\sum_{\mathrm{A}}$ depends on the specific

\footnotetext{
10 "In the sixteenth century the methods of [computing longitude] were so inaccurate that navigators were often in error as much as 500 miles" (Kline, 1972, p. 336). In 1712, the British government established a commission for the discovery of longitude
} 
characteristics of Algebra as a representation system and on the operators it allows to implement. Computation of symbolic expressions and mathematical proof are the key tools to decide whether a statement is valid or not. Indeed, symbolic representations are not the only ones to be available and to be used. Following $\mathrm{C}_{\mathrm{A}}$, a function can be associated with a graph — that is, a set of pairs $(\mathrm{x}, \mathrm{y})$ in the Cartesian plane (where $\mathrm{y}$ is the value of the function for a given $\mathrm{x}$ ). This possibility often suggests close relationships between $\mathrm{C}_{\mathrm{C}}$ and $\mathrm{C}_{\mathrm{A}}$ that raises the question of the relationship between graph and curve. While the graph is a possible representation of a function, displaying phenomena that algebraic expressions do not easily demonstrate (for example, the intersection of two lines), a curve is rather an evocation of the trajectory of a mobile point or of a geometric object, as Kline expresses it when describing Newton's conception (Kline, 1972, p. 339).

The general solution of partial differential equations expressing the vibrations of a finite string, subject to initial conditions, induced Euler to consider arbitrary functions that did not necessarily have an analytic representation. The existence of such arbitrary functions was controlled by physical arguments and was related to the various possible initial forms of the string. The emergence of a Relation conception, $\mathrm{C}_{\mathrm{R}}$, of function then required the development of new modes of representation $L_{R}$ and new control structures $\sum_{\mathrm{R}}$ in order to define what such functions could be and in order to work with them without any reference to an analytical representation. These developments took two centuries.

The conceptions of function we have modeled differ from each other in an essential way. The conception of curves as trajectories of a point, ascribed to Newton by Kline (1972, p. 339) is fundamentally different from the Dirichlet conception of a subset of the Cartesian product of two sets satisfying given constraints (which guarantees a unique image for each element of the source set). The crucial point here is that 
"function" does not refer to the same object in the two cases but to objects that are different in essence, despite the fact that in modern terms we could mathematically interpret them in the same framework.

Without going too far in the discussion of these points we must notice that each representation system we consider, taken by itself (with its semiotic characteristics), has a different displaying power (which can be defined as the capacity to show or to hide what should be shown). These differences can be better understood by considering (a) the operators that can be implemented and (b) the corresponding control systems.

\subsection{STUDENTS' CONCEPTIONS OF FUNCTION}

We focus on students from the secondary and post secondary levels. These students constitute the bulk of the population studied in the literature. They all have some knowledge of Algebra and they all have been exposed to classical elementary functions. A classic in this area, Vinner's (1992) study on students' concept image of function, identified eight components of students' conceptions of function:

- "The correspondence which constitutes the function should be systematic, should be established by a rule and the rule itself should have its own regularities";

- "A function must be an algebraic term";

- "A function is identified with one of its graphical or symbolic representations";

- "A function should be given by one rule";

- "A Function can have different rules of correspondence for disjoint domains provided that these domains are regular domains (like half lines or intervals);

- "A rule of correspondence which is not an algebraic rule is a function only if the mathematical community officially announced it as a function";

- "The graph of a function should be regular and systematic";

- “A function is a one-to-one correspondence". (Vinner, 1992, p. 200) 
These components of the concept image of function result from investigations carried out by Shlomo Vinner with students in the Jerusalem area at the beginning of the eighties. Since Vinner published this seminal work in 1983, these features have been confirmed as being largely common to students all over the world (Tall, 1996, pp. 297$301)$.

As they are presented to the reader, these features are not yet organized into conceptions. In particular one misses indications about their domain of validity as well as about the way they could be implemented in a problem-solving situation. One can notice that several of them are tightly related to one system of representation, either algebraic or graphical. Actually, representations are good starting points to shed light on the question of the differentiation of conceptions.

For example, from the students' point of view, the idea that a graph-curve should exist in relation to an algebraic expression is central, both representations having to conform to certain constraints ${ }^{11}$. By the expression 'graph-curve' we refer to two different entities that must be distinguished. This is well expressed by Sierpinska (1989) when she introduced the distinction between synthetic and analytic views of curves ${ }^{12}$ :

\footnotetext{
11 There is a rich literature on understanding functions and their representations. A common distinction is made between the process and object aspects of functions (Dubinsky and Harel, 1992; Sfard, 1991). Those aspects can be related to the students' uses of different representations of functions (DeMarois and Tall, 1999; Schwingendorf, Hawks, and Beineke, 1992). The distinction between the global approach and the point-wise approach to functions (Bell and Janvier, 1981; Even 1998) is critical as well, showing in particular that the capacity to deal with (graphical and algebraic) representations of functions or to move from one representation to another is related to the flexibility in using different approaches to functions. Because of limitations of space we do not elaborate on all those aspects here but we limit ourselves to the specific case of the graph/curve distinction.

12 Although she keeps using the word "curve" in both cases
} 
"Curve analytical view: a function is an 'abstract' curve in a system of coordinates; this means that it is conceived of points $(\mathrm{x}, \mathrm{y})$, where $\mathrm{x}$ and y are related to each other somehow." (Sierpinska, 1989, pp. 18).

"Curve, a synthetic view: [...] function is identified with its representation in the plane; it is a curve viewed in a concrete, synthetic way.” (Sierpinska, 1989, p. 17).

This distinction reminds us of the one that is usually made in mathematics between curve and graph: curve refers to a geometrical object, and graph to a representation of a function in the graphical representation system (one plots a graph). However, the distinction made by Sierpinska seems not to be exactly this one, since she added that the "relationship (between $x$ and $y$, the analytical view) can be given by an equation. But the curve does not represent the relation. Rather, it is represented by the equation." (Sierpinska, 1989, p. 17). This remark draws our attention to the confusion likely to be made by students between the geometric setting and the calculus setting (in the sense of setting proposed by Douady, 1985), which is facilitated by the identity of the diagrams used by both of them.

Thus, we suggest considering two types of student conceptions: the CurveAlgebraic and the Algebraic-Graph. To consider them in a more precise way we describe them by two quadruplets:

Curve-Algebraic conception: $\mathrm{C}_{\mathrm{CA}}=\left(\mathrm{P}_{\mathrm{CA}}, \mathrm{R}_{\mathrm{CA}}\right.$, Curve-Algebraic, $\left.\sum_{\mathrm{CA}}\right)$, Algebraic-Graph conception: $\mathrm{C}_{\mathrm{AG}}=\left(\mathrm{P}_{\mathrm{AG}}, \mathrm{R}_{\mathrm{AG}}\right.$, Algebraic-Graphic, $\left.\sum_{\mathrm{AG}}\right)$ These two conceptions apparently share the same representation system, algebraic and graphic, but these systems have different degrees of importance in both (this is suggested by their different order in their given name). In the case of the CurveAlgebraic conception, the criterion is that the curve must be related to an algebraic representation (its equation, in Sierpinska's terms). In the case of the Algebraic-Graph 
conception, the criterion is that the algebraic representation must be associated with a graph which one must be able to plot. The distinction between graph and curve is not very easy to make because both rely on a graphical representation. This difficulty is very likely to be one of the reasons why some students do not recognize in which setting they are working (and consequently they experience difficulty in knowing what is legitimate to do). It is by looking at the rules that both conceptions require one to abide by, the tools that they allow one to use, and the control structures they provide that we can shape the distinction.

The exploration and modeling of students' conceptions is a rather difficult job to accomplish when one can only rely on the evidence provided by tasks where students are directly asked to answer the question "what is a function?", or where they are invited to decide if graphs or descriptions of correspondences represent functions (e.g., "Does there exist a function all of whose values are equal to each other?" Vinner and Dreyfus, 1989, figure 1, p. 359).

One can notice two important points about such experiments: First, they show a distance between the answers to the question "what is a function?" and those to the tasks requiring a decision on descriptions of correspondences. This distance confirms the relationship between conceptions and problems. Different tasks (like providing a definition or describing a function) may call for different conceptions. This suggests that students' conceptions are less accessible in statements about a concept than in problem solving situations involving this concept. For this reason, the characterization of conceptions requires the provision of evidence for the relations between conceptions and problems. The second point concerns the type of tasks proposed to students. In none of these tasks students needed to perform actions in order to produce a solution but rather they had to activate control operators in order to produce a decision.Vinner himself emphasized the fragility of this type of investigation when he observed a large 
number of occurrences of what he called "irrelevant reasoning" that he defined as "[...] justification given by the student because he or she assumed it was the right thing to say (and no meaningful thought was involved)" (Vinner, 1992, p. 206).

This observation can be analyzed under the light of the very clear description by Castela (1995, p. 21) of the situation she used to explore students' conceptions of tangent. Castela assumed that the drawings she proposed to students were "straightforward," that their approximate character (they are sketches of functions) did not hide any surprising feature - the functions represented were what they seemed to be. ${ }^{13}$ One can then legitimately think that the observed situations may depend heavily on the quality of the experimental contract. ${ }^{14}$ The researcher claims that the investigation targets the students' conceptions, but it may be the case that what is observed is students' contingent opinions and not students' conceptions as expected. Students' answers might be a way to fulfill the teacher/observer expectation - this is exactly what Vinner feared. But indeed, how could it be different? Especially in the graphical representation system the tasks provided to students by Castela, used what we suggest be called function icons instead of functions' graphical representations. In order to understand this point, we invite the reader to consider such tasks from the point of view of the nature of the feedback the students can expect from the environment provided by the situation in which they are involved. They cannot perform any relevant action on the graphical representation since these representations are just sketches (see Castela's pictures or the tasks proposed by Vinner and Dreyfus).

\footnotetext{
13 "Les fonctions représentées sont bien ce qu'elles ont l'air d'être" [The functions represented are exactly those that seem represented] ; Castella (1995, p. ).

14 In particular, this (implicit) contract defines the way the students should understand the experimental situation.
} 


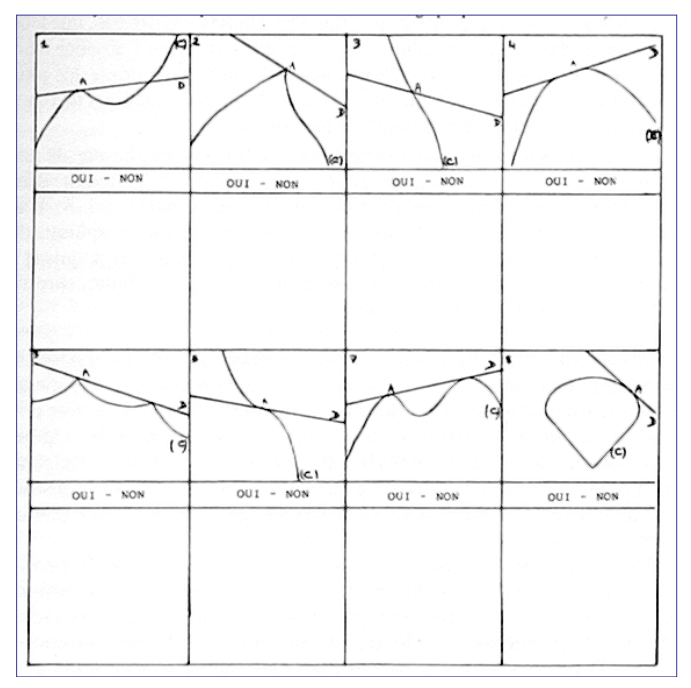

Figure 2 (from Castela, 1995, p. 17)

But, what are the problems for which students' conceptions provide tools allowing them to propose reasonable solutions (at least in the student's eyes)? Indeed, the characterization of a conception should not be separated from the characterization of the problem situation that provides evidence for it.

To go beyond the definition and investigate more problem-oriented situations is indeed what Vinner (1992) intended when he asked students to decide on the continuity or on the differentiability of a function. He concluded from his study that for students (i) for a "function to be continuous is the same as being defined and to be discontinuous is the same as being undefined at a certain point" (Vinner, 1992, p. 205), or (ii) "continuity or discontinuity is related to the graph" [e.g. 'a function is continuous because its graph can be drawn in one stroke'] (p. 206), or (iii) “there is a certain reference to the concept of limit" [e.g. "The function is continuous because it tends to a limit for every x'] (p. 207). Whereas the direct question "what is a function?" gave essentially an indication of possible elements of the control structures, we get here an insight about the tools students may have available.

Some of these tools clearly relate to a Curve-Algebraic conception. For example, drawing the graph $[\mathrm{y}=1$ if $\mathrm{x}>0$ and $\mathrm{y}=-1$ if $\mathrm{x}<0]$ is a tool which allows us to control 
the aspect of the graphical object (the graph shows a disruption) and so allows to conclude that the function $f(x)=\frac{|x|}{x}$ is discontinuous (Vinner's task B1). Other tools relate to an Algebraic-Graph conception (like the ones involving a criterion of limit).

Vinner did the same with the derivative, identifying (i) correct algebraic characterizations, or (ii) descriptions of symbolic manipulations to be performed, or (iii) correct definitions within the graphical representation system. But Vinner did not seem to have effective tools for describing the so-called incorrect solutions. This resulted in the use of attributes like "vague", "fuzzy" or "meaningless". Altogether these vague and fuzzy answers represent $46 \%$ of the sample of 119 students. We must realize here that students were confronted with graphical representations of functions and asked to decide and to justify whether they were continuous or not. In the case of the derivative they were directly asked to define it, answering the question "what is a derivative?" Again we observe the fragility of the data gathered, insofar as these tasks may well not reveal students' conceptions of derivative but their possible opinion offered in a rather embarrassing situation.

In order to decide or to justify a statement, one has to mobilize one's conception in a different way, more operational, than to define it, say, in abstracto. The point here is that what we learn from students discourse or work must be analyzed against the characteristics of the situation in which this discourse or work is produced. We could say that conceptions and problems are dual entities (Balacheff, 1995): In order to characterize students' conceptions one should provide them with meaningful problem situations, with enough complexity so that they can engage their conceptions in a 
significant way, demonstrating for us the tools they use and the nature of the control they involve in the task ${ }^{15}$.

Artigue (1992, p.130) gives us an excellent example of the benefit of coming back to the students' context when she analyses, in the case of the qualitative approach to differential equations, the false theorem: "if $\mathrm{f}(\mathrm{x})$ has a finite limit when $\mathrm{x}$ tends toward infinity, its derivative $\mathrm{f}^{\prime}(\mathrm{x})$ tends to 0 ". She wrote:

"In the field of differential equations, monotonicity conceptions may especially act as obstacles as on one hand, effective predictions are implicitly based on the extra-hypothesis of monotonicity and on the other hand, theorems have to get free of these extra-hypothesis. Let us be more explicit:

When sketching solution curves, we draw the simplest one compatible with the identified set of constraints, but in doing this, we add extra constraints concerning the convexity that can be expressed roughly in the following way: convexity has to be the least changing possible or, in algebraic terms, the sign of $\mathrm{f}^{\prime \prime}$, for a solution $\mathrm{f}$, has to be the most constant possible. So, $\mathrm{f}^{\prime}$ is implicitly the most monotonic possible." (ibid. p.130)

She concludes that the mentioned false theorem "can be seen as an instantiation of such an extra-hypothesis: if for $\mathrm{x}$ large enough, $\mathrm{f}^{\prime}$ is monotonic, then $\mathrm{f}^{\prime}$ has necessarily a limit (finite or not) and the unique limit compatible with an horizontal asymptote is 0 . In other words, by adding the condition $\mathrm{f}^{\prime}$ monotonic, this false theorem becomes a true one" (ibid.) Such an analysis of a tool (which is the actual status of theorems in students' practice) used by students, is evidence of the interaction between

\footnotetext{
15 Note that we do not pretend that this is enough to solve our diagnostic problem, but that it is a necessary condition.
} 
the graphic and the algebraic representation system, and the role played by the characteristics of the sphere of practice (a role which is in fact recognized by Vinner when he points to the phenomenon of "compartmentalization").

Let us then come back to the Curve-Algebraic conceptions and the AlgebraicGraph conceptions. We distinguish these conceptions by the type of tools and controls they involve in problem-situations, and their interactions with the representation system (either graphic or symbolic) on which they depend and which makes them tangible.

To state what the set $\mathrm{P}$ is in each case remains an open problem for research in mathematics education even in this domain, which has been heavily investigated. One may observe, at this point, that history is of no great help. Actually students' conceptions are very difficult to analyze against what history teaches us about the evolution of the concept of function. And indeed we would be very cautious with the idea that the "historical study of the notion of function together with its epistemological analysis helped us to analyze the student's mathematical behavior" (Sierpinska, 1989, p. 2). It is clear that the epistemological analysis is an essential tool, but the historical analysis may induce a view of the notion of function that hides the role played by the modern school context. The historical analysis will delineate the notion from the mathematical point of view, and from the cognitive point of view we must be prepared to see things in a rather different way. Actually Sierpinska $(1989$, p. 19) acknowledged that 'the students' conceptions are not faithful images of the corresponding historical conception." For example, a question one has to consider is that of knowing what could be the essential difference between the students' algebraic conceptions and the "corresponding" historical conceptions. It is also striking that tables play a very limited role if at all in situations involving functions: if they are present it is in relation to concrete situations in which the aim is less one of analyzing a function than one of analyzing the data (the function "disappears" behind its use as a tool for data analysis). 
Students' spheres of practice are radically different from the ones of the mathematicians that historians consider. The didactical system has first introduced students to "good" functions, mainly playing with two different settings: algebraic and graphical. As Sierpinska (1989) noticed, shapes of graphs of elementary functions can become prototypes of conceptions. Depending on the curriculum they have been exposed to, students have available more or less sophisticated tools in order to analyze some elementary algebraic formulas, and to describe the behavior of the corresponding functions. These spheres of practice may be described in detail following a close analysis of textbooks which are available to students (see Mesa, 2004, for a first investigation in this direction).

\subsection{A CASE STUDY: THE CURVE-ALGEBRAIC AND ALGEBRAIC-GRAPH CONCEPTIONS}

Our intention in this section is to demonstrate how the algebraic and the graphical representation system, the rules-tools, and the controls required in the problem lead to the differentiation of the Curve-Algebraic and the Algebraic-Graph conceptions of function, taking the case of students from the $12^{\text {th }}$ grade in France.

The experimental context was provided by the dynamic geometry environment Cabri-Geometry II ${ }^{16}$ (hereafter named Cabri). Cabri allows one to construct objects and display the dynamic relation between their graphical and algebraic representations (Gaudin 2002).

The diagram of a parabola in a system of coordinates was presented to the students. Some limitations on the manipulation of the drawing have been imposed in order to constrain the action of the students and open better opportunity for their conceptions to be elicited (see below the specification of the situation 1 and 2). This

\footnotetext{
16 Cabri-Geometry II is a dynamic geometry environment distributed by Texas Instruments.
} 
diagram could be turned around its vertex, by dragging the parabola's axis of symmetry.

The software would update dynamically the equation associated to the diagram after each of these manipulations (see figures 3 to 6 ).
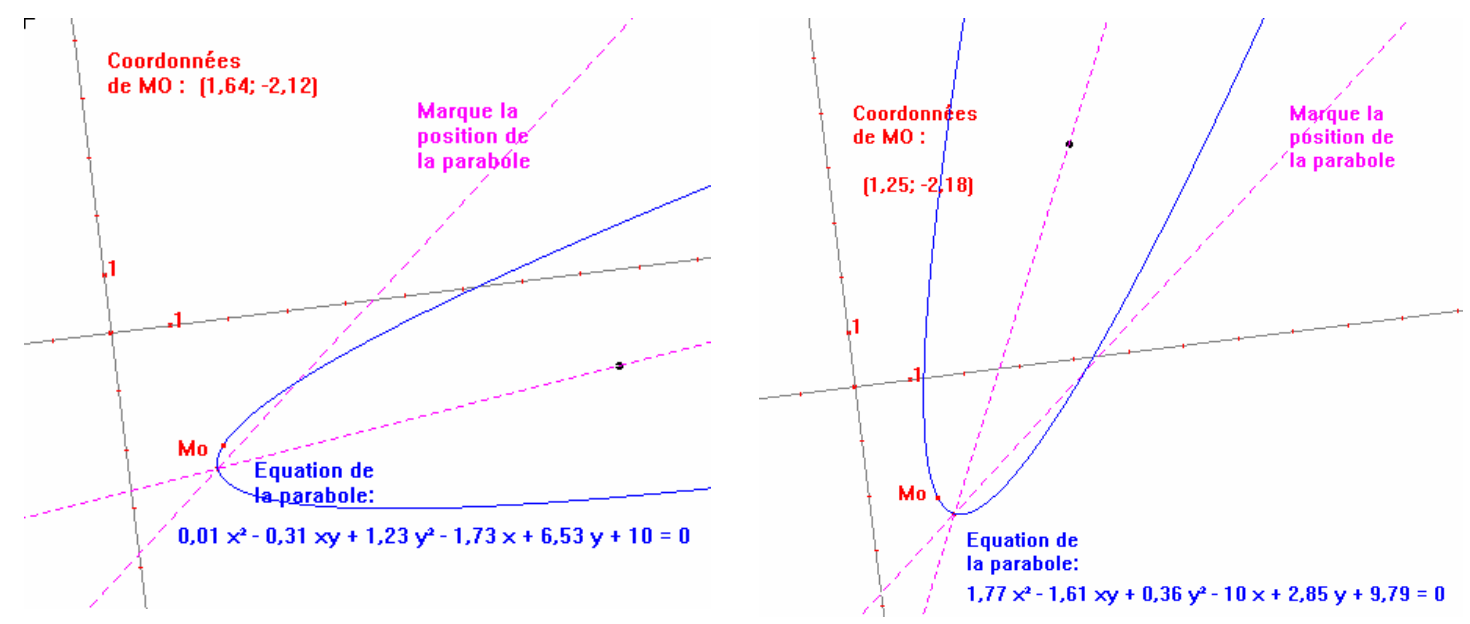

Figure 3

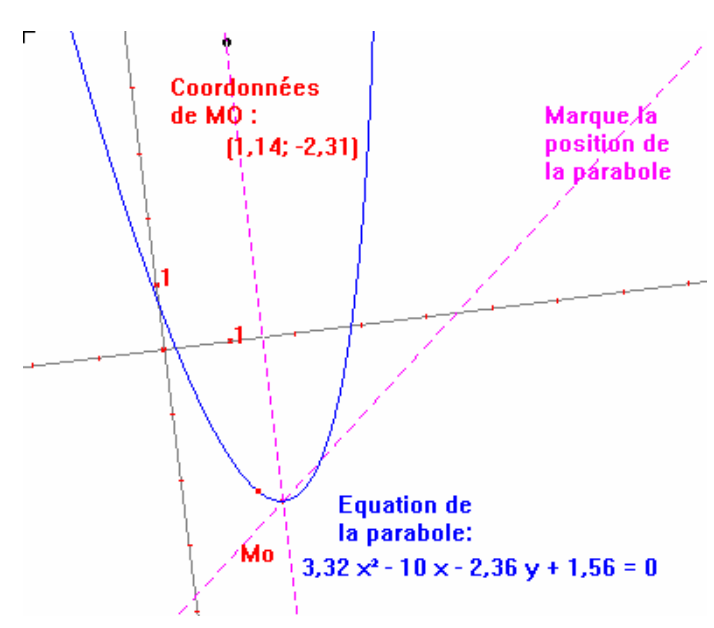

Figure 4

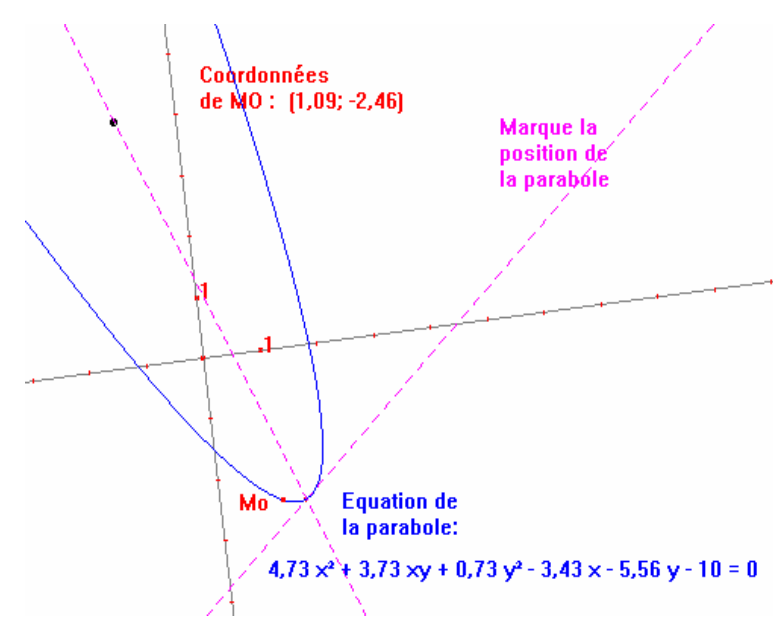

Figure 5

Figure 6

\section{Different positions of the parabola in Cabri}

The French text "Marque la position de la parabole", means that the marked line was drawn in order to keep a record of the initial position of the drawing so that the students could always come back to it if they 
wanted. The other French texts are: "Coordonnées de Mo" for " $\mathrm{M}_{\mathrm{o}}$ coordinates", and "équation de la parabole" for "equation of the parabola".

We asked students to give the equation of the line tangent to the parabola ${ }^{17}$ at point $\mathrm{M}_{0}$ and to draw this tangent (using Cabri, the students knew how to draw a straight line whose Cartesian equation was given).

Situation 1: the parabola could be manipulated by moving its axis of symmetry (grabbing a point given on this axis, see Figures 3 ) so that it could reach a "vertical" position (Figure 5) —in this position the parabola is the graph of a quadratic function.

Situation 2: the movements were constrained, the parabola could not turn completely around the vertex, hence it could not reach the vertical position as in situation 1; and so students could not get the familiar picture of a quadratic function.

$12^{\text {th }}$ grade students were supposed to know:

That a parabola whose equation is $y=a x^{2}+b x+c$ is the graph of the function $\mathrm{f}$ defined by $f(\mathrm{x})=\mathrm{ax}^{2}+\mathrm{bx}+\mathrm{c}$.

That an equation of the tangent to the graph of a function $f$ at point $\mathrm{M}_{0}\left(\mathrm{x}_{0}, \mathrm{y}_{0}\right)$ is $\mathrm{y}=f^{\prime}\left(\mathrm{x}_{0}\right)\left(\mathrm{x}-\mathrm{x}_{0}\right)+f\left(\mathrm{x}_{0}\right), f^{\prime}$ being the derivative of $f$.

Some rules of differentiation.

Nothing about conics.

\footnotetext{
${ }^{17}$ It is common in French mathematical classes, as it is in most of the books from different countries we have looked at, to use the word "parabola", either for the geometrical object or for the graph of the quadratic function. Its use leaves pragmatically open the choice of either a geometrical perspective or an algebraic perspective.
} 
In order to frame the analysis of students' problem-solving activity we sketch hereafter the strategies that could be expected in both situations:

\section{Situation 1:}

The capacity to control the position of the parabola allows reaching the vertical position to get the graph of a quadratic function $f$. Its algebraic representation is $f(\mathrm{x})=(1 / 2.36)\left(3.32 \mathrm{x}^{2}-10 \mathrm{x}+1.56\right)($ see Figure 5$)$.

The property "An equation of the tangent of a graph of a function $f$ at point $\mathrm{M}_{0}\left(\mathrm{x}_{0}, \mathrm{y}_{0}\right)$ is $\mathrm{y}=f^{\prime}\left(\mathrm{x}_{0}\right)\left(\mathrm{x}-\mathrm{x}_{0}\right)+f\left(\mathrm{x}_{0}\right)$, where $f^{\prime}$ is the derivative of $f$ ' is an operator which processes the algebraic expression of $f$.

One gets the equation of the tangent of the parabola $(y=-1.01 \mathrm{x}-1.17)$ and draws the tangent with Cabri.

Situation 2:

The parabola can not reach the vertical position anymore, but in the horizontal position it is the graph of a quadratic function in another system of coordinates defined by the same origin, the point $(0,-1)$ as the unit on the $\mathrm{x}$ axis and the point $(1,0)$ as the unit on the y axis (see Figure 7$)$.

The new system is associated to the change of variable $\mathrm{X}=-\mathrm{y}$ and $\mathrm{Y}=\mathrm{x}$. This change is a tool to find the equation $3.08 \mathrm{X}^{2}-2.04 \mathrm{Y}-9.23 \mathrm{X}+10=0$ of the parabola in the new system and to get the algebraic representation $f(X)=(1 / 2.04)$ $\left(3.08 X^{2}-9.23 X+10\right)$ of the function of which the parabola is a graph in the new system.

Like in situation 1, the property "An equation of the tangent of a graph of a function $f$ at point $\mathrm{M}_{0}\left(\mathrm{x}_{0}, \mathrm{y}_{0}\right)$ is $\mathrm{y}=f^{\prime}\left(\mathrm{x}_{0}\right)\left(\mathrm{x}-\mathrm{x}_{0}\right)+f\left(\mathrm{x}_{0}\right)$, where $f^{\prime}$ is the derivative of $f^{\prime \prime}$ is an operator which processes the algebraic expression of $\mathrm{f}$. One gets the equation of the tangent of the parabola $(Y=-1.20 X+3.06)$. The change of variable $X=-y$ and $Y$ 
$=\mathrm{x}$ is a tool to find the equation of the tangent in the initial system of coordinates: $1.20 \mathrm{y}$ $-\mathrm{x}+3.06=0$. One draws the tangent with Cabri .

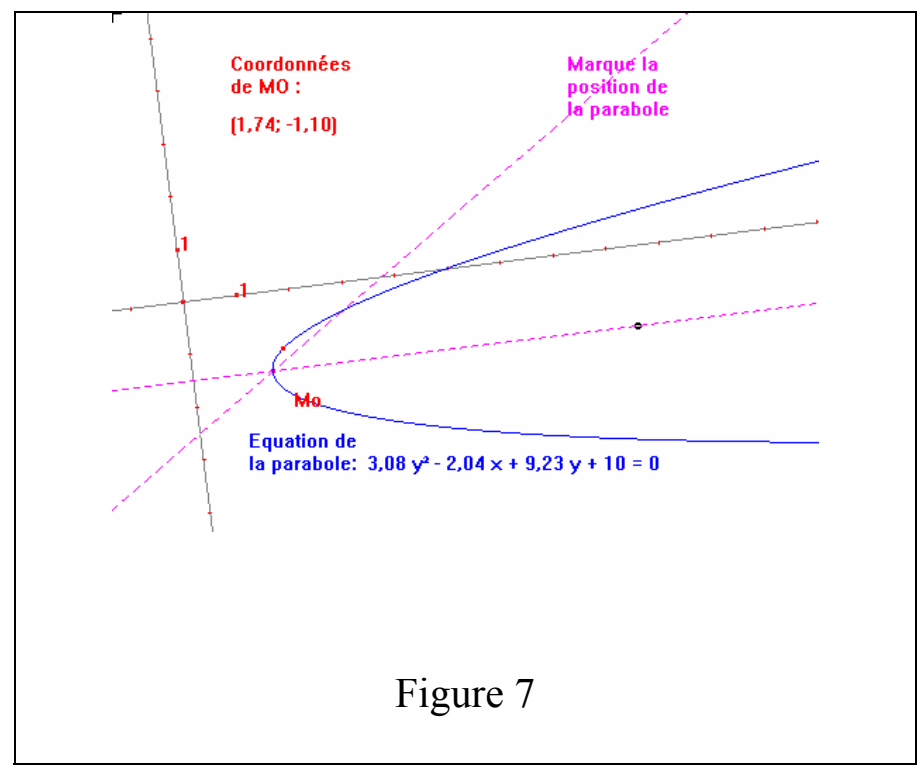

The drawing of a parabola on the screen can be conceptualized as a graph or as a curve. Recall from section 4.3, the graph of a function $f$ is the set of points $(\mathrm{x}, f(\mathrm{x}))$ in a system of coordinates; a curve is a geometrical object, which can be drawn independently from the existence of a system of coordinates. Considering the parabola as the graph of a quadratic function, is essential in order to associate controls to the tools involved in the above mentioned strategies.

We will present some aspects of the analysis of the observed behaviors of two pairs of students. André and Rémi were one pair, and Loïc and Sylvain were the other pair; each pair of students worked together on these problems. We have chosen these two case because they illustrate in a very good way both conceptions: Curve-Algebraic in the case of André and Rémi, and Algebraic-Graph ${ }^{18}$ in the case of Loïc and Sylvain.

18 For more details, see Gaudin (2005). 
From these students' point of view, getting the equation of the tangent of the parabola

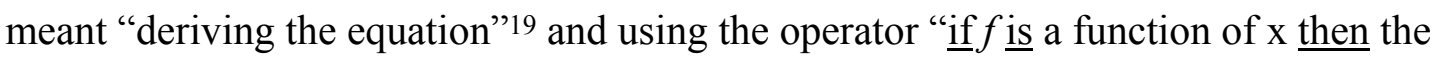
equation of the tangent at the point $\mathrm{M}\left(\mathrm{x}_{0}, f\left(\mathrm{x}_{0}\right)\right)$ is $\mathrm{y}=f^{\prime}\left(\mathrm{x}_{0}\right)\left(\mathrm{x}-\mathrm{x}_{0}\right)+f\left(\mathrm{x}_{0}\right)$ ". As long as the parabola was not the representation of a graph, students could not perform the rules of differentiation they knew (and so, use the operator and get the equation of the tangent). Their decisions and actions to make the equation in accordance with these rules revealed different controls and tools involved in the problem.

By identifying the controls used by André and Rémi or by Loïc and Sylvain to establish if an equation could be derived or not in situation 1 , we can discriminate both conceptions.

For André and Rémi, the equation could be derived if its form was $[\mathrm{y}=$ $<$ an expression of $x>$ ]. Since this was not the case, they tried to change the position of the parabola. They moved it to the vertical position. They chose this position while controlling the equation which, as a result, became simpler and simpler (when $y$ disappeared from the equation the students said "that's good;" when the coefficient of xy decreased, "that's perfect"). They obtained an equation that they called a "neat equation" that could be derived.

Sylvain and Loïc found the equation on the screen really complicated ("monstrous"). They decided that the equation was not the representation of a function because the graph did not pass the vertical line test (there were two values for one $x$ ). They stated that the equation could not be derived. The control on the derivability was based on the form of the equation which had to be $[y=($ some $x$, no $y)]$. Sylvain anticipated that $x y$ and $\mathrm{y}^{2}$ should disappear in the

\footnotetext{
${ }^{19}$ We specify below what is meant to "derive the equation" for each students' pair.
} 
equation when the parabola would reach the vertical position, so they decided to get this position.

The actions of both student pairs in situation 1 are the same: moving the parabola to the vertical position and getting the equation of the tangent as described in the expected strategy. But the means of control and the associated representation system differ in an important way. André and Rémi's means of control refer essentially to the algebraic representation system: getting an adequate symbolic writing of the equation. In Sylvain's and Loïc's case these refer to the graphic and algebraic representation system: satisfying the vertical line test to get an equation of the form: $[y=($ some $x$, no $y)]$.

These controls play an essential role in students' decisions in situation 2 . Noticing that the parabola cannot reach the vertical position any more, both students' pairs had to change their strategies.

André and Rémi decided to move the parabola to the horizontal position because the equation appeared then to be the simplest one they could expect. The obtained an equation $\left(3.08 \mathrm{y}^{2}-2.04 \mathrm{x}+9.23 \mathrm{y}+10=0\right)$ which they described as "nice" and "the best." But this equation was not yet in accordance with the rule of differentiation and students proposed to change $x$ with $y$ and $y$ with $x$. Again, their control is essentially algebraic. They were skeptical of the legitimacy of such a change. They proposed to change the system of coordinates into the new one according to the mapping of variables: $X=-y$ and $Y=x$. They got an expression that they could differentiate $\left(f(x)=(1 / 2.04)\left(3.08 X^{2}-9.23 X+\right.\right.$ 10) — one should note that they wrote " $x$ " and not "X", in " $f(x)$ ". The important 
point here is the meaning students ascribed to the change of system. They did not relate this change to the other objects of the situation: they used the first coordinate of $\mathrm{M}_{0}$ in the operator "if $f \underline{\text { is }}$ a function of $\mathrm{x}$ then the equation of the tangent at the point $\mathrm{M}\left(\mathrm{x}_{0}, f\left(\mathrm{x}_{0}\right)\right)$ is $\mathrm{y}=f^{\prime}\left(\mathrm{x}_{0}\right)\left(\mathrm{x}-\mathrm{x}_{0}\right)+f\left(\mathrm{x}_{0}\right)$." Consequently, the equation of the tangent was not rewritten in the initial system prior to drawing the tangent (as described by the "expected" strategies), and the equation of the tangent line was not correct. Clearly, the change of system was not associated to a control in the graphical representation system. It was only associated to a control on the symbolic writing of the equation conforming to $[y=$ (expression $o f(x)]$.

Loïc moved the parabola to the horizontal because this position appeared to him to be "better than any position." Sylvain did not consider this position as a better one to solve the problem. This opinion was consistent with the vertical line test he used in situation 1 and is confirmed by the presence of $y^{2}$ in the equation ("I don't see... how will you cope with the $y^{2}$ ?"). He proposed to change the system of coordinates: the new proposed system being the one in which the parabola satisfied the vertical line test, and so, the one in which the parabola was the graph of a function. Thus, unlike the other student pair, it was a control in the graphical representation system which led to choose the new system of coordinates. This control allowed a distinction graph/curve more effective than getting a nice equation. More effective means in this context that the control was associated to new tools used by the students: reading the coordinates of $\mathrm{M}_{0}$ in the new system, getting the equation of the tangent in which the parabola is a graph, and then writing this equation in the initial system to draw the tangent. 
The identification of different conceptions in these two cases is possible by looking at the controls, the tools, and the associated representation systems the students used to solve the problems. In the present situation, the actions we observed refer to rather different controls and do not define the same settings of work.

In the case of the Curve-Algebraic conception, the control associated to the operator "if $f \underline{\text { is } ~ a ~ f u n c t i o n ~ o f ~} \mathrm{x}$ then the equation of the tangent at the point $\mathrm{M}\left(\mathrm{x}_{0}, f\left(\mathrm{x}_{0}\right)\right)$ is $\left.\mathrm{y}=f^{\prime}\left(\mathrm{x}_{0}\right)\left(\mathrm{x}^{-} \mathrm{x}_{0}\right)+f\left(\mathrm{x}_{0}\right)\right)^{\prime}$ is an algebraic control. The parabola is a geometric object designated by an equation and some of its positions are more or less operational from the point of view of this control. Thus, the algebraic tools and transformations (change of variable) do not apply on the objects of the geometric setting (the parabola, $\mathrm{M}_{0}$, the tangent straight line). Calculus is reduced to symbolic transformations.

In the case of the Algebraic-Graph conception, graphic controls (recognizing the parabola as a graph, reading the situation in a new system) are related to algebraic tools (the operator "if $f \underline{\text { is }}$ a function of $\mathrm{x}$ then the equation of the tangent at the point $\mathrm{M}\left(\mathrm{x}_{0}, f\left(\mathrm{x}_{0}\right)\right)$ is $\mathrm{y}=f^{\prime}\left(\mathrm{x}_{0}\right)\left(\mathrm{x}-\mathrm{x}_{0}\right)+f\left(\mathrm{x}_{0}\right)$ ", the change of variables that works on every object of the system). Because of this relation, Calculus can be based on variables linked by an equation and/or a graph.

Moreover, it should be noted that the drawings and symbolic representations are not used in the same way. Eventually, they are not components of the same representation systems, despite the similarities of the signs used. In the case of the curve-algebraic conception, the diagram is the reification of a geometrical object, in the case of the algebraic-graph, the diagram is an object in the graphical system which is 
considered in close coordination with an object from the algebraic representation system.

\section{CONCLUSION: CONCEPTION, KNOWING, AND CONCEPT}

Modeling students' knowing of mathematics is a difficult task, which we need to achieve in order to be able to better design teaching situations or learning environments. To contribute to the search for a solution we have proposed a definition of the notion of "conception" and a modeling framework. This approach is an attempt to capture the core of a possible characterization of a conception seen as a situated knowing providing the tools and the controls to solve problems from a given sphere of practice. This proposition is intended to overcome the epistemological contradiction of an individual being a rational person but still likely to demonstrate contradictory behaviors from the point of view of an observer. Moreover, it provides an instrument to more precisely account for the possible meaning of the students' behaviors and outcomes by describing more precisely how the representations, actions, and controls they use are related and contribute to the problem-solving process.

One may notice that, as a result of our definition of conception, we may now have three notions which seem likely to compete in the mathematics education discourse, namely: conception, knowing and concept. Our contribution would not improve matters unless we were able to relate these three notions in a clear manner, demonstrating their complementarities. This is possible by defining a knowing as a set of conceptions. A knowing is a set of conceptions ascribed to a subject, whereas a conception represents an "instantiation" of this knowing by a given situation. The universe of an individual can be described by means of several different spheres of practice each calling for different conceptions - i.e. different instances of his or her 
knowing. It is only from the point of view of the observer that all these instances relate to the same knowing. The individual is not necessarily or always aware of the possible relations among his or her own conceptions. In order to stimulate this awareness, a special event is necessary, which consists of a situation bringing to the fore a problem which forces us to consider two different spheres of practice which are usually mutually exclusive. This is the basis for the design of a learning situation which could stimulate the students feeling of the intellectual need ${ }^{20}$ to express their conceptions and possibly to reconsider them.

In order to be able to establish the links between the conceptions he or she is ascribing to the student the observer needs to translate each system of representation into a single system of representation - in general, his or her own system of representation. All our analyses, as researchers in mathematics education, are based on this possibility. This aspect of representations and their use in research is essential, although rarely noticed: we can model a conception, relate and compare conceptions, only if we can ascribe to them representation systems, and if we can relate these systems of representation to ours. This indeed imposes constraints on our analysis which could be a kind of anachronism or over interpretation of learners' behaviors and understanding. We claim that the only way to cope with this inherent difficulty to our task is to make things as explicit as possible. The modeling framework proposed in this paper could contribute to achieving such explicitness.

Considering now the term "concept": we suggest to use concept to refer to the set of all the knowings sharing the same content of reference. This answers positively

\footnotetext{
${ }^{20}$ We borrow here the expression proposed by Harel (2006).
} 
the question posed by Rolf Biehler at the BACOMET IV last meeting21: "Couldn't we say that the meaning of a mathematical concept is the synthesis of all of its uses?" On the other hand, we are at some distance from Sfard's (1991) proposal that, "the word 'concept' (sometimes replaced by 'notion') will be mentioned whenever a mathematical idea is concerned in its 'official' form — as a theoretical construct within 'the formal universe of ideal knowledge'; the whole cluster of internal representations and associations evoked by the concept - the concept's counterpart in the internal, subjective 'universe of human knowing'-will be referred to as 'conception"” (ibid. p.3). However, if the view of "concept" could be considered more pragmatic in our presentation, the view of "conception" we have developed is not so far away from the one Sfard proposed. The fact that the two notions of "concept" and "conception" are sufficient for Sfard is coherent with the fact that the level of knowing is necessary only when one wants to reconstruct the totality of the epistemic subject, considering the variety of the situations in which he or she is engaged. If the situation and what is at stake in it are precise enough the notion of conception is sufficient. What explains that, well defined or not, considered from the "misconception" perspective or from a more general perspective, conception has always played a central role in mathematics education.

Acknowledgement: this paper has a long history. It has benefited from the comments and questions of the participants in the BACOMET IV project "Meaning in mathematics education" (1993-1996) and extensive discussions with participants to the Rutgers RISE project "Understanding students understanding” (2001). The writing of

\footnotetext{
21 We refer to a question posed by Rolf Biehler in a working paper he shared in the context of the BACOMET project IV "Meaning in mathematics education" (1996).
} 
this paper was finished in San Diego, where it benefited from the stimulating input from Guershon Harel and his group. Eventually, I would like to thank especially Patricio Herbst for the final polishing of this text and its careful editing.

This final version follows a significantly different one available at the following link: http://hal.ccsd.cnrs.fr/ccsd-00001510.

\section{REFERENCES}

Arsac G., Balacheff N., Mante M. (1992) Teacher's role and reproducibility of didactical situations. Educational Studies in Mathematics 23 (5) 5-29.

Artigue M. (1991) Épistémologie et didactique. Recherches en didactique des mathématiques. 10(2/3) 241-285.

Artigue M. (1992) Functions from an algebraic and graphic point of view: cognitive difficulties and teaching practices. In: Dubinsky E., Harel G. (eds.) The concept of Function. (MAA Notes Vol. 25, 109-132). Mathematical Association of America.

Bachelard G. (1938) La formation de l'esprit scientifique. Paris : Vrin.

Balacheff N. (1987) Processus de preuves et situations de validation. Educational Studies in Mathematics 18(2) 147-176.

Balacheff N. (1995) Conception, connaissance et concept. In : Grenier D. (ed.) Didactique et technologies cognitives en mathématiques, séminaires 1994-1995 (pp.219-244). Grenoble : Université Joseph Fourier.

Balacheff N. (1998) Construction of meaning and teacher control of learning. In : Tinsley D. J., Johnson D. C. (eds.) Information and Communication Technologies in School Mathematics (pp. 111-120). Chapman \& Hall. 
Balacheff N., Margolinas C. (2005) cKф Modèle de connaissances pour le calcul de situations didactiques. In: Mercier A., Margolinas C. (eds.) Balises en didactique des mathématiques (pp.75-106). Grenoble: La Pensée sauvage.

Bourdieu P. (1990) The logic of practice. Stanford, CA: Stanford University Press [English translation of : Le sens pratique. Paris : Les éditions de Minuit. 1980] Breidenbach D., Dubinsky, Hawks J., Nichols D. (1992) Development of the process conception of function. Educational Studies in Mathematics 23, 247-285.

Brousseau G. (1997) Theory of didactical situations in mathematics. Dordrecht: Kluwer Academic Publishers.

Bell A., Janvier C. (1981) The interpretation of graph representing situations. For the Learning of Mathematics 2(1), 34-42.

Castela C. (1995) Apprendre avec et contre ses connaissances antérieures. Recherches en didactique des mathématiques. 15(1) 7-47.

Confrey J. (1986) "Misconceptions" accross subject matters: charting the course from a constructivist perspective. Annual meeting of the American Educational Research Association. (unpublished manuscript).

Confrey J. (1990) A review of the research on students conceptions in mathematics, science, and programming. In: Courtney C. (ed.) Review of research in education. American Educational Research Association 16, pp. 3-56.

D’ Ambrosio U. (1993) Etnomatemática. São Paulo: Editora Atica.

DeMarois P., Tall D. (1999) Function: Organizing principle or Cognitive Root? Proceedings of the twenty third international conference for the psychology of mathematics education (Vol. 2, pp. 257-264). Haifa, Israel.

Dhombres J. (1988) Un Texte d'Euler sur les Fonctions Continues et les Fonctions Discontinues, Véritable Programme d'Organisation de l'Analyse au 18ième 
Siècle. Cahier du Séminaire d'Histoire des Mathématiques, Université Pierre et Marie Curie, Paris.

Douady R. (1985) The interplay between different settings. Tool-object dialectic in the extension of mathematical ability. In: Streefland L. (ed.) Proceedings of the ninth international conference for the psychology of mathematics education (Vol. 2, pp. 33-52). Utrecht: State University of Utrecht.

Dubinsky E., Harel G. (1992) The nature of the process conception of function. In: Dubinsky E., Harel G. (eds.) The concept of Function. (MAA Notes Vol. 25, 195-213). Mathematical Association of America.

Edwards C. H. Jr. (1979) The historical development of calculus. Berlin: Springer-Verlag.

Even R. (1998) Factors involved in linking representations of functions. Journal of Mathematical Behavior 17(1), 105-121.

Furth H. G. (1969) Piaget and Knowledge. Theoretical foundations. NJ: Prentice-Hall

Gaudin N. (2002) Conceptions de fonction et registres de représentation, étude de cas au lycée. For the Learning of Mathematics (pp. 35-47).

Gaudin N. (2005) Place de la validation dans la conceptualisation, le cas du concept de function. $\mathrm{PhD}$ thesis. Grenoble : Université Joseph Fourier, Grenoble1.

Glasersfeld E. von (1984) An introduction to radical constructivism. In : Watzlawick P. (ed.) The invented reality (pp. 17-40). New York : Norton.

Harel G. (2006, in press) The DNR system as a conceptual framework for curriculum development and instruction. In: Lesh R., Kaput J., Hamilton, E. (eds.) Foundations for the Future: The Need for New Mathematical Understandings \& Abilities in the 21st Century. Hillsdale, NJ: Lawrence Erlbaum Associates. 
Kleiner I. (1989) Evolution of the function concept: a brief survey. The College Mathematics Journal 20(4) 282-300.

Kline M. (1972) Mathematical Thought from Ancient to Modern Times. New York: Oxford University Press.

Lave J. (1988) Cognition into practice. Cambridge: Cambridge University Press.

Mesa, V. (2004). Characterizing practices associated with functions in middle school textbooks: An empirical approach. Educational Studies in Mathematics 56, 255286.

Monna A. F. (1972), The Concept of Function in the $19^{\text {th }}$ and $20^{\text {th }}$ Centuries, in Particular with Regard to Discussions between Baire, Borel and Lebesgue. Archive for History of Exact Sciences 9 (1) 57-84

Nuñes T., Carraher D., Schliemann A. (1983) Mathematics in streets and schools. Cambridge: Cambridge University Press.

Pichot A. (1994) Pour une approche naturaliste de la connaissance. Lekton 4(2) 199-241.

Rabardel P. (1995) Qu'est-ce qu'un instrument? Les dossiers de l'Ingénierie éducative. 19, 61-65.

Resnick L., Collins A. (1994) Cognition and Learning. Pre-print. Learning Research and Development Center. University of Pittsburgh.

Robert A. (1992) Problèmes méthodologiques en didactique des mathématiques. Recherches en didactique des mathématiques. 12(1) 33-58.

Robert A. (1993) Présentation du point de vue de la didactique des mathématiques sur les métaconnaissances. In : Baron M., Robert A. (eds.) 
Métaconnaissances en IA, en EIAO et en didactique des mathématiques. RR LAFORIA 93/18. (pp.5-18). Paris: Institut Blaise Pascal.

Salin M.-H. (1976) Le rôle de l'erreur dans l'apprentissage des mathématiques de l'école primaire. IREM de Bordeaux.

Schoenfeld A. (1985) Mathematical Problem Solving. Orlando: Academic Press.

Schoenfeld A. (ed) (1987) Cognitive Science and Mathematics Education. Hillsdale : Lawrence Erlbaum Associates.

Schoenfeld A.H., Smith J., Arcavi A. (1993). Learning: The microgenetic analysis of one student's evolving understanding of a complex subject matter. In R. Glaser (Ed.), Advances in Instructional Psychology (vol. 4, pp. 55-175). Mahwah, NJ: Lawrence Erlbaum Associates.

Schwingendorf K., Hawks J., Beineke J. (1992) Horizontal and vertical growth of the students' conception of function. In: Dubinsky E., Harel G. (eds.) The concept of Function. (MAA Notes Vol. 25, 133-152). Mathematical Association of America.

Sfard A. (1991) On the dual nature of mathematical conceptions: reflections on processes and objects as different sides of the same coin. Educational Studies in Mathematics 22, 1-36.

Sierpinska A. (1989) On 15-17 years old students' conceptions of functions, iteration of functions and attractive fixed points. Institut de Mathématiques, preprint 454. Varsovie: Académie des Sciences de Pologne.

Smith D. E. (1958) History of mathematics. (Vol. II, esp. chap X). New York: Dover Publications Inc.

Soury-Lavergne S. (eds.) (2003) Baghera Assessment Project, designing an hybrid and emergent educational society. Cahier Leibniz 81. 
http://www-leibniz.imag.fr/NEWLEIBNIZ/LesCahiers/Cahiers2003.html

Stewart J. (1994) un système cognitif sans neurones : les capacités

d'adaptation, d'apprentissage et de mémoire du système immunitaire. Intellectika 18 , $15-43$.

Tall D. (1996) Functions and calculus. In: Bishop A. et al. (eds.)

International Handbook of Mathematics Education (pp. 289-326). Dordrecht:

Kluwer Academic Publishers.

Thurston W. P. (1994) On proof and progress in mathematics. Bulletin of the American Mathematical Society 30(2) 161-177.

Vergnaud G. (1981) Quelques orientations théoriques et méthodologiques des recherches françaises en didactique des mathématiques. Recherches en didactique des mathématiques. 2(2) 215-231.

Vergnaud G. (1991) La théorie des champs conceptuels. Recherches en didactique des mathématiques. 10(2/3) 133-169.

Vinner S. (1983) Concept definition, concept image and the notion of function. International Journal of Mathematical Education in Science and Technology 14, 293-305

Vinner S. (1987) Continuous functions - images and reasoning in college students. In: Bergeron J. C., Herscovics N., Kieran C. (eds.) Proceedings of the Eleventh International Conference for the Psychology of Mathematics Education (Vol. 3 pp. 177-183). Montréal, Canada: Université de Montréal.

Vinner S. (1992) The function concept as a prototype for problems in mathematics education. In: Dubinsky E., Harel G. (eds.) The concept of Function. (MAA Notes Vol. 25, 195-213). Mathematical Association of America.

Vinner S., Dreyfus T. (1989) Images and definition for the concept of function. Journal for Research in Mathematics Education 20(4) 356-366. 
Youschkevitch A. P.(1976), The Concept of Function up to the Middle of the19th Century. Archives for History of Exact Sciences 16 (1) 37-85. 